\title{
Infection and expression of Toll-like receptors in lymphoid malignancy patients after autologous stem cell transplantation
}

\author{
KATARZYNA WICHERSKA-PAWŁOWSKA, JUSTYNA RYBKA, BOŻENA JAŹWIEC, \\ ELŻBIETA KALICIŃSKA, ALEKSANDRA BOGUCKA-FEDORCZUK, TOMASZ WRÓBEL
}

Department of Hematology, Blood Neoplasms and Bone Marrow Transplantation, Wroclaw Medical University, Wroclaw, Poland

\begin{abstract}
Introduction: High-dose chemotherapy with autologous stem cell transplantation (ASCT) is one of the main strategies for the treatment of haematological neoplasms. Infections are the most common cause of morbidity and mortality from the ASCT procedure. However, it is challenging to predict when these complications are likely to arise. Toll-like receptors (TLRs) are present on various immune cells and play a broad role in immune surveillance. The aim of the study was to investigate the association between the expression of TLR genes and the occurrence of infections in patients treated with ASCT.

Material and methods: TLR expression was analysed in 60 patients who underwent ASCT. The median age was 54 years. Blood samples were taken before high-dose chemotherapy and at the time of haematopoietic recovery after ASCT.

Results: The expression of Toll-like receptor 4 (TLR4) was significantly higher in patients before ASCT than after transplantation. The expression of Toll-like receptor 9 (TLR9) was significantly higher in patients after ASCT than before transplantation. The expression of TLR9 and TLR4 at the start of the procedure was significantly lower in patients who went on to develop a bacterial infection after ASCT. Moreover, we also observed a significant positive correlation between the expression of TLR9 and neutrophil recovery time after ASCT.

Conclusions: Our findings suggest that TLRs could be useful biomarkers to predict and monitor infections in patients treated with ASCT.
\end{abstract}

Key words: Toll-like receptors, stem cell transplantation, haematological malignancies.

(Cent Eur J Immunol 2021; 46 (4): 463-469)

\section{Introduction}

High-dose chemotherapy with autologous stem cell transplant (ASCT) is a widely used therapy in the treatment of haematopoietic neoplasms. However, ASCT is associated with profound deficiencies in the function of the immune system. The proportion of ASCT recipients who go on to develop severe infections and associated complications varies, but infections are still a significant cause of mortality and morbidity. Age, general health, co-morbidities, and the number of previous treatment regimens are some factors known to influence the risk of such complications. In a study by Weaver et al., the mortality rate due to infections after high-dose chemotherapy and ASCT was $1.5 \%$ [4]. However, new prognostic markers are still being explored, the knowledge of which would allow us to determine the risk of severe complications in individual patients before the start of high-dose chemotherapy.
Toll-like receptors (TLRs) are a group of proteins that are actively involved in the function of the immune system. Most TLRs are expressed on the surface of cells, although TLR3 and TLRs 7-9 are intracellular [1]. TLRs are found on haematopoietic cells, such as B lymphocytes, T lymphocytes, monocytes, macrophages, dendritic cells, and NK cells, as well as on non-haematopoietic cells, including vascular endothelial cells, gastrointestinal and respiratory epithelial cells, adipocytes, cardiomyocytes, and fibroblasts. Their diverse expression means TLRs come into contact with many pathogens attempting to penetrate the body. Their recognition of these pathogens can stimulate the immune system.

One of the mechanisms of TLR function is the activation of the NF- $\kappa \mathrm{B}$ transcription factor. The TLRs that are expressed on macrophages and dendritic cells initiate an innate immune response, including the activation of phagocytosis processes and the production of inflammato-

Correspondence: Justyna Rybka, MD, PhD, Department of Hematology, Blood Neoplasms and Bone Marrow Transplantation, Wroclaw Medical University, Wybrzeże L. Pasteura 4, 50-367 Wroclaw, Poland, phone: +48 717842576 , fax: +48 71 784 12 10, e-mail: rybka.justyna@o2.pl

Submitted: 12.08.2021; Accepted: 23.11.2021 
Table 1. Patient clinical data

\begin{tabular}{|c|c|}
\hline \multicolumn{2}{|c|}{ Patient data $(N=60)$} \\
\hline Gender & $\begin{array}{l}\text { Female: } 27 \\
\text { Male: } 33\end{array}$ \\
\hline Median age & 54 years (range: $25-65$ ) \\
\hline Diagnosis & $\begin{array}{c}\text { MM: } 20 \\
\text { nHL: } 20 \\
\text { DLBCL }-8 \\
\text { FL }-5 \\
\text { MCL }-7 \\
\text { HL: } 20\end{array}$ \\
\hline Disease status & $\begin{array}{l}\text { Complete remission: } 25 \\
\text { Partial remission: } 35\end{array}$ \\
\hline $\begin{array}{l}\text { Median neutrophil } \\
\text { recovery time }\end{array}$ & 14 days (range: $10-16$ days) \\
\hline Neutropenic fever & 30 patients \\
\hline Infections & 24 patients (4 MM, $20 \mathrm{nHL}+\mathrm{HL})$ \\
\hline Bacterial infection & $\begin{array}{l}\text { Klebsiella pneumoniae: } 10 \\
\text { Enterococcus faecalis HLAR: } 8\end{array}$ \\
\hline
\end{tabular}

ry chemokines and cytokines such as interleukin (IL)-12, IL-6 and type I interferon (type I IFN). TLRs are often described as a bridge between an innate immune response and an acquired immune response [3].

This study aimed to evaluate the expression of Tolllike receptor genes and their correlation with the incidence of infection after ASCT in patients with haematological malignancies.

\section{Material and methods}

\section{Study participants}

The expression of Toll-like receptor genes (TLR2, $T L R 4$, and TLR9) was measured in 60 patients undergoing ASCT. The median age of the patients was 54 years (range: 25-65 years). ASCT was performed due to multiple myeloma (MM) in 20 patients, for non-Hodgkin's lymphoma (nHL) in another 20 patients, and Hodgkin's lymphoma (HL) in 20 patients. The healthy control group include 10 volunteers. The median age of healthy controls was 51 years (range: 26-64 years).

Peripheral blood samples were taken for analysis before the start of high-dose chemotherapy, before ASCT, and at the time of haematopoietic regeneration after stem cell transplantation (median: 14 days; range: 10-16 days after ASCT). In patients with MM, high doses of melphalan were administered $\left(200 \mathrm{mg} / \mathrm{m}^{2}\right.$ or $140 \mathrm{mg} / \mathrm{m}^{2}$, depending on the patients' age and general health) during the conditioning regimen before ASCT. Patients with nHL and HL received high-dose chemotherapy according to the BEAM protocol (carmustine, etoposide, cytosine arabinoside, and melphalan).
A median of $3.38 \times 10^{6}$ autologous CD34-positive cells per kilogram of body weight were transplanted. The median duration of neutropenia was 10 days in patients with MM (range: 9-15 days) and 12 days in patients with $\mathrm{nHL}$ and $\mathrm{HL}$ (range: 11-17 days). The median granulocyte regeneration time (defined as > 500 neutrophils/ $\mu$ l) was 14 days in the entire study population (range: 10-16 days). Febrile neutropenia was observed in 30 patients (8 patients with MM, 12 patients with nHL and 10 patients with HL). Microbiologically confirmed infection was found in 24 cases (4 patients with MM and 20 patients with nHL and HL). The most frequently isolated pathogen was Klebsiella pneumoniae (10 cases). Infection was confirmed in stool culture in 8 patients, and in blood culture in 2 patients. In 8 patients, Enterococcus faecalis was isolated from the faeces. For prophylaxis of infections, ciprofloxacin, fluconazole, aciclovir and trimethoprim were administered to patients before ASCT. The median response time to antimicrobial treatment in the patients with infection was 4 days (range: 2-10 days).

All patients and healthy volunteers signed informed consent forms in order to participate in the study. The study was approved by the Bioethics Committee of the Medical University of Wroclaw. The clinical data of the patients are presented in Table 1.

\section{Real-time PCR}

The relative expression of Toll-like receptors TLR2, TLR4, and TLR9 was assessed by real-time polymerase chain reaction (PCR) using TaqMan Assays (Life Technologies/Thermo Fisher). Beta glucuronidase (GUSB) served as an endogenous control. The reaction was carried out on a 7500 Real-Time PCR instrument (Life Technologies) using Gene Expression Master Mix (Life Technologies/ Thermo Fisher). The comparative CT method was used to compare the expression of patients with healthy controls.

Statistical analysis was conducted using STATISTICA 12 software (StatSoft, Poland). For quantitative variables, arithmetic means (X) and standard deviations (SD) of the estimated parameters were calculated for the study groups. The distribution of variables was tested using Lilliefors and Shapiro-Wilk W tests. In cases of independent quantitative variables with normal distribution, a $t$-test for independent variables was used. In cases of variables with a non-normal distribution, the $t$-test for dependent variables was applied to the quantitative variables of the normal distribution. In cases of quantitative dependent variables with non-normal distribution, Wilcoxon's pair sequence test was applied. In order to define the relationships between the studied variables, correlation analysis was performed. Results at the level of $p<0.01$ were considered statistically significant.

\section{Results}

In comparison to the control group, expression of TLR4 was decreased in patients $(\triangle \mathrm{Ct}$ TLR4 $22.21 \pm 0.32$ vs. 
Table 2. Comparison of TLR values before and after aut ologous stem cell transplantation (ASCT)

\begin{tabular}{|c|c|c|c|c|}
\hline Variable & Parameter & Before ASCT $(N=60)$ & After ASCT $(N=60)$ & $p$-value \\
\hline \multirow[t]{4}{*}{ TLR2 Ct } & $N$ & 60 & 60 & 0.067 \\
\hline & Mean (SD) & $22.4(1)$ & $22.06(0.94)$ & \\
\hline & Median (IQR) & $22.13(21.7-23.09)$ & $22.07(21.59-22.54)$ & \\
\hline & Range & $20.61-24.58$ & $19.97-24.39$ & \\
\hline \multirow[t]{4}{*}{ TLR2 dCt } & $N$ & 60 & 60 & 0.22 \\
\hline & Mean (SD) & $-0.01(0.96)$ & $0.28(1.08)$ & \\
\hline & Median (IQR) & $-0.18(-0.68-0.58)$ & $0.33(-0.25-0.85)$ & \\
\hline & Range & $-2.15-2$ & $-2.98-3.09$ & \\
\hline \multirow[t]{4}{*}{ TLR2 2exp.dCt } & $N$ & 41 & 40 & 0.211 \\
\hline & Mean (SD) & $1.25(0.97)$ & $1.58(1.38)$ & \\
\hline & Median (IQR) & $0.88(0.62-1.5)$ & $1.26(0.84-1.8)$ & \\
\hline & Range & $0.23-4.01$ & $0.13-8.5$ & \\
\hline \multirow[t]{4}{*}{ TLR4 Ct } & $N$ & 60 & 60 & 0.005 \\
\hline & Mean (SD) & $22.93(0.93)$ & $22.4(0.64)$ & \\
\hline & Median (IQR) & $22.83(22.29-23.37)$ & $22.28(22.04-22.86)$ & \\
\hline & Range & $20.15-25.11$ & $21.14-24.08$ & \\
\hline \multirow[t]{4}{*}{ TLR4 dCt } & $N$ & 60 & 60 & 0.515 \\
\hline & Mean (SD) & $0.52(0.87)$ & $0.64(0.7)$ & \\
\hline & Median (IQR) & $0.38(0.07-0.99)$ & $0.48(0.26-0.92)$ & \\
\hline & Range & $-2.61-2.79$ & $-1.52-2.42$ & \\
\hline \multirow[t]{4}{*}{ TLR4 2exp.dCt } & $N$ & 60 & 60 & 0.889 \\
\hline & Mean (SD) & $1.71(1.18)$ & $1.74(0.92)$ & \\
\hline & Median (IQR) & $1.31(1.05-1.99)$ & $1.39(1.2-1.9)$ & \\
\hline & Range & $0.16-6.92$ & $0.35-5.37$ & \\
\hline \multirow[t]{4}{*}{ TLR9 Ct } & $N$ & 60 & 60 & 0.071 \\
\hline & Mean (SD) & $28.59(1.21)$ & $29.05(1.08)$ & \\
\hline & Median (IQR) & $28.7(27.61-29.24)$ & $29.2(28.44-29.69)$ & \\
\hline & Range & $25.79-30.68$ & $27.04-31.86$ & \\
\hline \multirow[t]{4}{*}{ TLR9 dCt } & $N$ & 60 & 60 & 0.001 \\
\hline & Mean (SD) & $6.18(1.34)$ & $7.28(1.22)$ & \\
\hline & Median (IQR) & $6.03(5.21-7.09)$ & $7.27(6.63-7.91)$ & \\
\hline & Range & $3.48-8.76$ & $4.16-10.25$ & \\
\hline \multirow[t]{4}{*}{ TLR9 2exp.dCt } & $N$ & 41 & 41 & 0.008 \\
\hline & Mean (SD) & $110.19(108.14)$ & $216.61(208.07)$ & \\
\hline & Median (IQR) & $65.3(36.9-136)$ & $154.3(99.3-240.9)$ & \\
\hline & Range & $11.2-433.8$ & $17.8-1221.1$ & \\
\hline
\end{tabular}

$11.91 \pm 70.22, p<0.01)$, while TLR2 gene expression was higher in patients than in healthy individuals ( $\triangle \mathrm{Ct}$ TLR2 $6.46 \pm 9.58$ vs. $0.98 \pm 0.43, p<0.05)$. TLR9 gene expression was higher in the control group than in haematological patients ( $\triangle$ Ct TLR9 $13.65 \pm 3.29$ vs. $3.35 \pm 1.93, p<0.05$ ).

The expression of TLR4 was statistically significantly higher in patients who had not yet had transplant-related, high-dose chemotherapy than in those who had undergone
ASCT (Ct TLR4 $22.93 \pm 0.93$ vs. $22.4 \pm 0.64$ ). The expression of TLR9 was significantly lower before ASCT than in patients who had undergone ASCT (dCt TLR9 6.18 \pm 1.34 vs. $7.28 \pm 1.22$, respectively, $p<0.01$ ). The results are presented in Table 2 and in Figures 1 and 2.

The expression of TLR4 and TLR 9 measured before the start of high-dose chemotherapy was significantly lower in patients who presented symptoms of infection in 


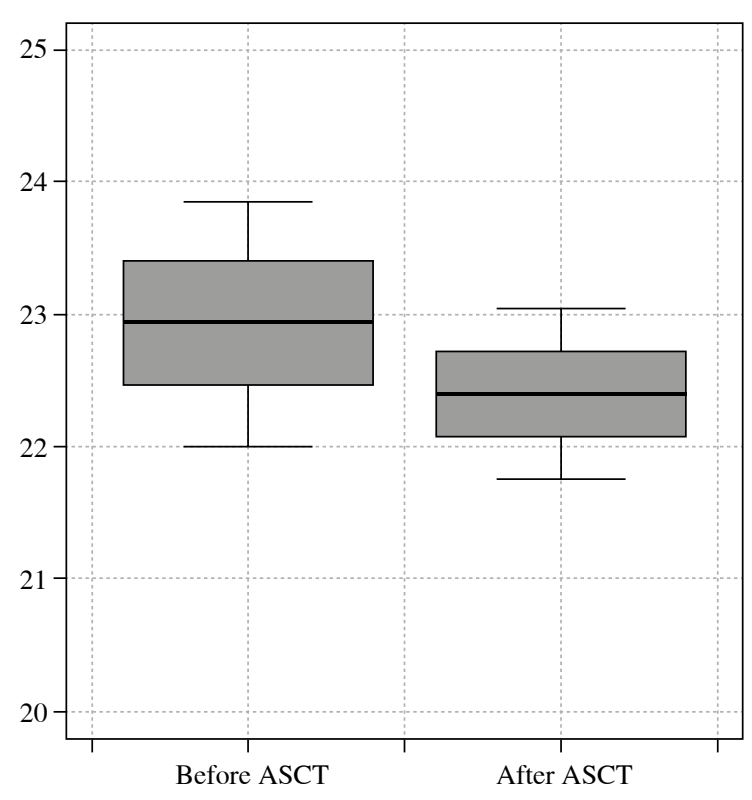

Fig. 1. TLR 4 value before and after autologous stem cell transplantation (ASCT)

the post-transplant period (Ct TLR4 $22.73 \pm 1.07$ vs. 23.07 \pm 0.81 and Ct TLR9 $28.5 \pm 1.24$ vs. $26.71 \pm 1.18$. respectively, $p<0.01)$. In patients with a clinically significant bacterial infection as a post-transplant infectious complication, significantly higher TLR 9 expression was observed compared to patients without any signs of an infection (Ct TLR9 $116.34 \pm 123.67$ vs. $105.83 \pm 98.23$ ). Such a relationship was not observed for TLR4 and TLR2 expression. $T L R 9$ expression and neutrophil cell growth after stem cell transplantation were positively correlated $(r=0.4075$, $p=0.023$ ). We detected no significant differences in TLR expression or infection rate between patients with MM, nHL, and HL. TLR expression was similar in patients with infection and MM, nHL and HL. The results are presented in Table 3.

\section{Discussion}

Infections are a common complication following ASCT. Depending on the period of bone marrow aplasia in which they appear, their course can be severe and can even lead to the death of the patient. Infections with Gram-positive and Gram-negative bacteria occur in about $20 \%$ of patients after autotransplantation, including bacteraemia in $7-8 \%$ of patients. Viral infections are observed in about $10-11 \%$ of patients after ASCT. Invasive mycoses are quite rare [5]. The mortality associated with severe infections after autotransplantation is estimated at around 2-4\% of patients [5-7]. Therefore, new factors and prognostic markers that enable the identification of patients with a higher risk of infection are of clinical importance.

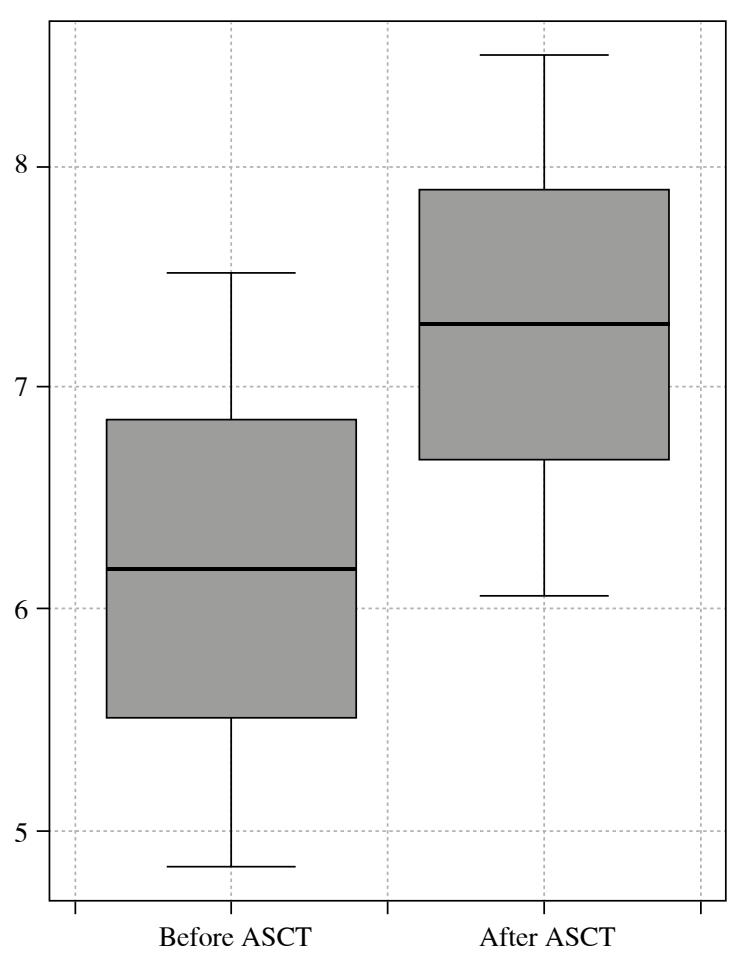

Fig. 2. TLR 9 value before and after autologous stem cell transplantation (ASCT)

The role of TLRs in the post-transplantation course remains unclear. The mechanisms of TLR action in solid organ transplantation have been much more thoroughly examined. Studies have shown that TLR11 plays a crucial role in the development of infections after renal transplantation. The most frequent infection-related complications are asymptomatic bacteriuria, cystitis, and pyelonephritis. These infections increase the risk of early mortality following transplantation [8].

TLR11 acts as a physiological barrier that protects the body against the penetration of uropathogens $[8,9]$. Studies on mice have shown that TLR11 is expressed in liver, kidney, bladder, and vascular endothelial cells, and has an affinity with a uropathogenic $E$. coli strain, thereby affecting local immunity in the urogenital tract [10]. It has also been revealed that higher TLR11 expression strengthens immunity against Toxoplasma gondii [11]. Finally, Shi et al. reported that invasive Salmonella infection occurred in mice with diminished TLR11 levels [12].

Innate immunity, of which TLRs are a critical element, plays an essential protective role against pathogens after a liver transplant. This protective role is particularly important when it comes to infections of the hepatitis $\mathrm{C}$ virus (HCV). Recurrence of $\mathrm{HCV}$ infection after liver transplantation is common [13-15], and HCV reactivation causes aggressive liver fibrosis and graft rejection in approximately $30 \%$ of $\mathrm{HCV}$-infected patients $[16,17]$. Eid 
Table 3. Comparison of TLR values before autologous stem cell transplantation (ASCT) in patients with infection and without infection

\begin{tabular}{|c|c|c|c|c|}
\hline Variable & Parameter & Without infection after ASCT $(N=17)$ & Infection after ASCT $(N=24)$ & $p$-value \\
\hline \multirow[t]{4}{*}{ TLR2 Ct } & $N$ & 24 & 17 & 0.1665 \\
\hline & Mean (SD) & $22.55(0.95)$ & $22.18(1.06)$ & \\
\hline & Median (IQR) & $22.46(21.78-23.12)$ & $21.96(21.58-22.57)$ & \\
\hline & Range & $20.8-24.24$ & $20.61-24.58$ & \\
\hline \multirow[t]{4}{*}{ TLR2 dCt } & $N$ & 24 & 17 & 0.1835 \\
\hline & Mean (SD) & $0.17(0.99)$ & $-0.27(0.89)$ & \\
\hline & Median (IQR) & $-0.02(-0.5-0.78)$ & $-0.37(-0.77-0.17)$ & \\
\hline & Range & $-1.51-2$ & $-2.15-1.45$ & \\
\hline \multirow[t]{4}{*}{ TLR2 2exp.dCt } & $N$ & 24 & 17 & 0.1835 \\
\hline & Mean (SD) & $1.43(1.11)$ & $1(0.67)$ & \\
\hline & Median (IQR) & $0.99(0.71-1.72)$ & $0.77(0.59-1.12)$ & \\
\hline & Range & $0.35-4.01$ & $0.23-2.74$ & \\
\hline \multirow[t]{4}{*}{ TLR4 Ct } & $\mathrm{N}$ & 24 & 17 & 0.1492 \\
\hline & Mean (SD) & $23.07(0.81)$ & $22.73(1.07)$ & \\
\hline & Median (IQR) & $23.21(22.45-23.41)$ & $22.51(22.17-23.18)$ & \\
\hline & Range & $21.84-25.11$ & $20.15-24.9$ & \\
\hline \multirow[t]{4}{*}{ TLR4 dCt } & $N$ & 24 & 17 & 0.1492 \\
\hline & Mean (SD) & $0.7(0.78)$ & $0.28(0.96)$ & \\
\hline & Median (IQR) & $0.56(0.15-1.11)$ & $0.17(-0.05-0.78)$ & \\
\hline & Range & $-0.49-2.79$ & $-2.61-1.9$ & \\
\hline \multirow[t]{4}{*}{ TLR4 2exp.dCt } & $N$ & 24 & 17 & 0.1492 \\
\hline & Mean (SD) & $1.9(1.36)$ & $1.44(0.83)$ & \\
\hline & Median (IQR) & $1.48(1.11-2.15)$ & $1.12(0.97-1.71)$ & \\
\hline & Range & $0.71-6.92$ & $0.16-3.73$ & \\
\hline \multirow[t]{4}{*}{ TLR9 Ct } & $N$ & 24 & 17 & 0.005 \\
\hline & Mean (SD) & $28.5(1.24)$ & $26.71(1.18)$ & \\
\hline & Median (IQR) & $28.73(27.46-29.27)$ & $26.63(27.72-29.24)$ & \\
\hline & Range & $25.79-30.51$ & $26.96-30.68$ & \\
\hline \multirow[t]{4}{*}{ TLR9 dCt } & $N$ & 24 & 17 & 0.7835 \\
\hline & Mean (SD) & $6.26(1.39)$ & $6.12(1.29)$ & \\
\hline & Median (IQR) & $6.07(5.01-7.3)$ & $5.77(5.51-6.83)$ & \\
\hline & Range & $3.48-8.45$ & $4.6-8.76$ & \\
\hline \multirow[t]{4}{*}{ TLR9 2exp.dCt } & $N$ & 24 & 17 & 0.003 \\
\hline & $\operatorname{Mean}(\mathrm{SD})$ & $105.83(98.23)$ & $116.34(123.67)$ & \\
\hline & Median (IQR) & $67.15(32.25-157.38)$ & $54.7(45.7-113.7)$ & \\
\hline & Range & $11.2-349.2$ & $24.2-433.8$ & \\
\hline
\end{tabular}

et al. demonstrated that the Arg753Gln TLR2 polymorphism correlates with progressive cirrhosis of the transplanted liver, graft rejection and patient death after liver transplantation due to HCV-dependent cirrhosis [18].

The role of TLRs in infectious complications after stem cell transplantation has not yet been clearly defined. In a prospective analysis, Skert et al. assessed the expression of TLRs in T lymphocytes and monocytes in a population of 35 patients after bone marrow stem cell transplantation and its correlation with infectious complications. The authors found that TLR 9 expression in T lymphocytes correlates negatively with bacterial infections. A correlation 
was also observed between TLR7 expression and fungal infections in this patient population [19].

In this study, we found that the expression of TLR 4 and TLR 9 before the start of the transplant procedure was statistically significantly lower in patients who had severe infectious complications in the later period. Additionally, $T L R 9$ expression significantly increased in patients with an active infection compared to patients without infection after transplantation. The physiological function of TLR4 is to stimulate the production of tumour necrosis factor $\alpha$ (TNF- $\alpha$ ), interleukin (IL)-1, and IL-12 after binding with the pathogen-associated molecular pattern (PAMP) ligand of the pathogenic agent. The immune system is only activated when TLR4 acts in conjunction with the antigens CD14 and CD11b/CD18 [9, 20]. TLR9 acts by stimulating IL-12, monocytes, macrophages and NK cells. TLR9 is often activated by bacterial DNA, which results in the creation of a natural defence mechanism against bacteria $[20,21]$. Consistently, experiments have shown that blocking the gene for the TLR9 receptor results in inhibition of activity against bacterial proteins [23, 24]. Lower expression of TLRs causes reduced synthesis of cytokines and chemokines, which leads to a generalised reduced immune response [22].

We also observed a positive correlation between TLR9 and the number of neutrophils during the period of bone marrow regeneration, which may indicate a role of TLRs in the reconstitution of the immune system following transplantation.

\section{Conclusions}

The role of TLRs in the immunological processes which determine immunity against infectious agents is crucial. As demonstrated by the results of our research, and supported by previous publications, lower expression of individual TLRs (especially TLR4 and TLR9) may correlate with a higher risk of infections, especially in immuno-incompetent patients after stem cell transplantation.

\section{Ethics approval and consent to participate}

All patients and healthy volunteers signed informed consent forms in order to participate in the study. The study was approved by the Bioethics Committee of the Medical University of Wroclaw.

All methods were carried out in accordance with relevant guidelines and regulations mentioned in the manuscript.

\section{Founding}

This work was financed by Wroclaw Medical University.

The authors declare no conflict of interest.

\section{References}

1. Yu L, Wang L, Chen S (2010): Endogenous toll-like receptor ligands and their biological significance. J Cell Mol Med 14: 2592-2603.

2. Kawai S, Akira T (2007): Signaling to NF-kappa B by Tolllike receptors. Trends Mol Med 13: 460-469.

3. Pasare R, Medzhitov C (2005): Toll-like receptors: linking innate and adaptive immunity. Adv Exp Med Biol 560: 11-18.

4. Weaver CH, Schwartzberg LS, Hainsworth J, et al (1997): Treatment-related mortality in 1000 consecutive patients receiving high-dose chemotherapy and peripheral blood progenitor cell transplantation in community cancer centers. Bone Marrow Transplant 19: 671-678.

5. Barton TD, Collis T, Stadtmauer E, Schuster MG (2001): Infectious complications the year after autologous bone marrow transplantation for treatment of breast cancer. Clin Infect Dis 32: 391-395.

6. Auner HW, Zebisch A, Ofner P, et al. (2005): Evaluation of potential risk factors for early infectious complications after autologous peripheral blood stem cell transplantation in patients with lymphoproliferative diseases. Ann Hematol 84: 532-537.

7. Pagano L, Caira M, Nosari A, et al. (2007): Fungal infections in recipients of hematopoietic stem cell transplants: results of the SEIFEM-B-2004 study - Sorveglianza Epidemiologica Infezioni Fungine Nelle Emopatie Maligne. Clin Infect Dis 45: 1161-1170.

8. Foxman B, Brown P (2003): Epidemiology of urinary tract infection, transmision and risk factors, incidence, and costs. Infect Dis Clin North Am 17: 227-241.

9. Johnson JR, Russo TA (2005): Molecular epidemiology of extraintestinal pathogenic [uropathogenic] Escherichia coli. Int J Med Microbiol 295: 383-404.

10. Zhang D, Zhang G, Hayden MS, et al. (2004): A Toll like receptor that prevents infection by uropathogenic bacteria. Science 303: 1522-1526.

11. Bird L (2005): A new ligand for TLR11. Nat Rev Immun 168: 554-561.

12. Shi Z, Cai Z, Yu J, et al. (2012): Toll-like receptor 11 [TLR11] prevents Salmonella penetration into the murine Peyer patches. J Biol Chem 287: 43417-43423.

13. Yoshida O, Kimura S, Jackson EK, et al. (2013): CD39 expression by hepatic myeloid dendritic cells attenuates inflammation in liver transplant ischemia-reperfusion injury in mice. Hepatology 58: 2163-2175.

14. Berenguer M, Prieto M, Rayon JM, et al. (2000): Natural history of clinically compensated hepatitis $\mathrm{C}$ virus-related graft cirrhosis after liver transplantation. Hepatology 32: 852-858.

15. Prieto M, Berenguer M, Rayon JM, et al. (1999): High incidence of allograft cirrhosis in hepatitis $\mathrm{C}$ virus genotype $1 \mathrm{~b}$ infection following transplantation: relationship with rejection episodes. Hepatology 29: 250-256.

16. Rosen HR, Gretch DR, Oehlke M, et al. (1998): Timing and severity of initial hepatitis $C$ recurrence as predictors of longterm liver allograft injury. Transplantation 30: 731-738.

17. Papatheodoridis GV, Patch D, Dusheiko GM, Burroughs AK (1999): The outcome of hepatitis C virus infection after liver transplantation - is it influenced by the type of immunosuppression? J Hepatol 30: 731-738.

18. Eid AJ, Brown RA, Paya CV, Razonable RR (2007) Association between toll-like receptor polymorphism and the outcome of liver transplantation for chronic hepatitis $\mathrm{C}$ virus. Transplantation 84: 511-516. 
19. Skert C, Fogli M, Garaffa E, et al. (2014): A specific Toll-like receptor profile on $\mathrm{T}$ lymphocytes and values of monocytes correlate with bacterial, fungal and cytomegalovirus infections in the early period of allogeneic stem cell transplantation. Transpl Infect Dis 16: 697-712.

20. Hemmi H, Takeuchi, Kawai T (2000): A Toll-like receptors recognises bacterial DNA. Nature 408: 740-746.

21. Sousa CR (2004): Toll-like receptors and dendritic cells for whom the bug tolls. Sem Immun 16: 27-34.

22. Janssens S, Beyaert R (2003): Role of Toll-like receptors in pathogen recognition. Clin Microbiol Rev 16: 637-646.

23. Modlin RL (2000): A Toll for DNA vaccines. Nature 408: 659-660.

24. Verthelyi D, Zeuner RA (2003): Differential signaling by CpG in DCs and B cells: not just TLR9. Trend Immun 24: 519-522. 